\title{
The Pollution Characteristic of Polycyclic Aromatic Hydrocarbons (PAHs) in Typical Sewage Irrigation Area in North of China
}

\author{
Jiale Li ${ }^{1}$, Caixiang Zhang ${ }^{1 *}$, Yihui Dong ${ }^{1}$, Xiaoping Liao ${ }^{1}$, Bin $\mathrm{Du}^{2}$, Linlin Yao ${ }^{1}$ \\ ${ }^{1}$ State Key Lab of Biogeology and Environmental Geology, China University of Geosciences, Wuhan, China \\ ${ }^{2}$ China National Administration of Coal Geology General Prospecting Institute, Beijing, China \\ Email: jllee.cug@gmail.com, *zeno448@163.com
}

Received 2013

\begin{abstract}
This research aims to investigate the pollution characteristic of PAHs in Xiaodian sewage irrigation area. The result shows that the concentrations of $\Sigma$ PAHs range from 47.94 to $46432.85 \mathrm{ng} / \mathrm{g}$ while that of the total components of the 16 kinds of PAHs are $5969.81 \mathrm{ng} / \mathrm{g}$. PAHs with for rings and more than 4 rings are the main and important pollutants in topsoils of Xiaodian District. The main input of PAHs is combustion source, and the main pollution source in this area is fired coal. The topsoils in Xiaodian District are polluted by human activity in varying degrees. 23 of all 31 topsoil samples have been heavily polluted, especially those located nearby developed industrial townships and irrigation channels.
\end{abstract}

Keywords: Pollution Characteristic; Polycyclic Aromatic Hydrocarbons (PAHs); Typical Sewage Irrigation Area

\section{Introduction}

Due to the shortage of water resource for agriculture irrigation, sewage irrigation has become an effective approach to deal with this problem since 1950s [1,2]. However, sewage contains lots of contaminations such as heavy metals, soluble salt and other organic contaminations which are teratogenic and mutagenic such as polycyclic aromatic hydrocarbons [3].

Polycyclic aromatic hydrocarbons (PAHs) are compounds containing two or more fused benzene rings in linear, angular, and cluster like arrangements. They are mainly derived from incomplete fossil fuel combustion, volatilization of uncombusted petroleum, biomass burning and the early diagenesis of organic matter. PAHs exist in the environments ubiquitously and many of them are carcinogenic and mutagenic to human beings [4-6]. Due to their negative effects, U.S. Environmental Protection Agency (EPA) defined 16 kinds of PAHs as priority pollutants [5], they are naphthalene (Nap), acenaphthylene (Acy), acenaphthene (Ace), fluorene (Flo), phenanthrene (Phe), anthracene (Ant), fluoranthene (Fla), pyrene (Pyr), benz[a]anthracene (BaA), chrysene (Chry), benzo[b]fluoranthene $(\mathrm{BbF})$, benzo[k]fluoranthene $(\mathrm{BkF})$, benzo[a]pyrene (BaP), indeno[1,2,3-cd]pyrene (Ind), dibenzo[a,h]anthracene (DiA), and benzo[g,h,i]perylene

\footnotetext{
*Corresponding author.
}

(BghiP).

Many authors have reported the pollution characteristic of PAHs in soil. The background concentration of soils in village is $1-1300 \mathrm{ng} / \mathrm{g}$, the concentration of agricultural soils is 5 - $900 \mathrm{ng} / \mathrm{g}$ while $145-166,000 \mathrm{ng} / \mathrm{g}$ in the polluted soils [7]. The concentration of polluted $\Sigma$ 16PAHs in the surface sedimentary of river, estuary and sea reached 6 - $8399 \mathrm{ng} / \mathrm{g}-\mathrm{dw}$ [8]. The concentration of PAHs in industrialized area, coal mining area and oil producing area in Welsh reached a high level of 54,500 $\mathrm{ng} / \mathrm{g}$ while $2330 \mathrm{ng} / \mathrm{g}$ in the general industrial zone, the average range is $108-54,500 \mathrm{ng} / \mathrm{g}$ [9].

Xiaodian sewage irrigation area lies in the southeast of Taiyuan city, north of China. This area has a 30 years' history of sewage irrigation since 1970s. The seawage flowed through the area via East Main Channel which lies in the west of the area, irrigated the entire field and then flowed to Fenhe River through Beizhang Drainage and Taiyu Drainage. This study aimed to investigate the pollution characteristic of PAHs in typical sewage irrigation area-Xiaodian sewage irrigation area.

\section{Materials and Methods}

\subsection{Sample Collection and Preparation}

As shown in the Figure 1, the topsoils were collected with $2 \mathrm{~km} \times 2 \mathrm{~km}$ grids in August, 2010. 31 samples 


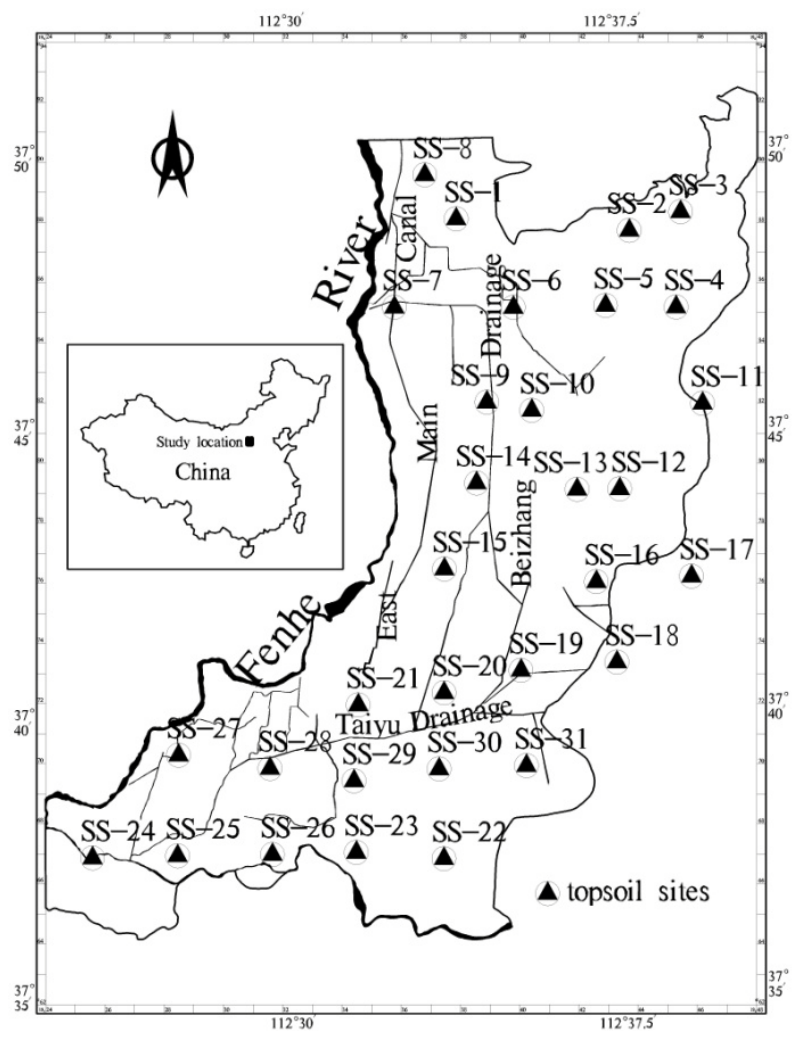

Figure 1. Location of Xiaodian sewage irrigation area and the sampling sites.

were positioned in aluminium boxes and marked with the sample number, sealed with parafilm, refrigerated in freezer at $0^{\circ} \mathrm{C}$ as soon as possible then air dried in sunless place before analyses.

\subsection{Analytical Procedure}

20 ng of recovery surrogate standards which were mixed by deuterated PAHs standards (naphthalene-d8, acenaphthene-d10, phenanthrene-d10, chrysene-d12, and perylene-d12) were added to $10 \mathrm{~g}$ of samples. Then, added $120 \mathrm{~mL}$ of Dichloromethane (DCM) to the samples and Soxhlet-extracted for $24 \mathrm{~h}$. Concentrated the extracted liquid to $2 \mathrm{~mL}$, filtered by alumina/silica gel (1:2 v:v) column with $30 \mathrm{~mL}$ of DCM-hexane at a radio of 2:3, concentrated to $0.2 \mathrm{~mL}$, added internal standard (hexamethylbenzene, $1000 \mathrm{ng}$ ) before GC-MS analyses.

16 kinds of PAHs which were defined as priority pollutants by EPA were determined. $1 \mu \mathrm{l}$ sample was injected in splitless/split mode. PAHs compounds were separated on a HP-5 capillary column $(30 \mathrm{~m} \times 0.25 \mathrm{~mm}$ i.d. $\times 0.25$ film thickness) with nitrogen as carrier gas at a flow rate of $2.5 \mathrm{~mL} / \mathrm{min}$ in a constant flow mode and determined by GC-MS (Agilent 6890N/5975MS). The GC operating conditions were: injectortemperature, $280{ }^{\circ} \mathrm{C}$; ion source temperature, $180^{\circ} \mathrm{C}$; temperature program: held at $60^{\circ} \mathrm{C}$ for $2 \mathrm{~min}$, ramped to $290^{\circ} \mathrm{C}\left(3^{\circ} \mathrm{C} \mathrm{min}^{-1}\right)$, held for $30 \mathrm{~min}$. The MSD was operated in the electron impact mode at $70 \mathrm{eV}$ and the selectedion-monitoring mode. Quantitative determinations at the mass range $\mathrm{m} / \mathrm{z}$ 50 - 500. Data acquisition and processing operated by a HP Chemstation software.

No detected target compounds were found in the daily method blanks. Surrogate standards were added to all the samples and analyzed for quality assurance and control. The mean recoveries for all the 31 samples were: $55 \% \pm$ $15 \%$ for naphthalene-d8, $66 \% \pm 12 \%$ for acenaphthaned10, $74 \% \pm 15 \%$ for phenanthrene-d10, $69 \% \pm 8 \%$ for chrysene-d12, $84 \% \pm 6 \%$ for perylene-d12.

\section{Results and Discussion}

As can be seen from Table 1 and Figure 2, the average concentration of a sing component in 16 kinds of PAHs detected in topsoils of Xiaodian District ranges from $18.70 \mathrm{ng} / \mathrm{g}$ to $944.22 \mathrm{ng} / \mathrm{g}$, while that of the total components of the 16 kinds of PAHs are $5969.81 \mathrm{ng} / \mathrm{g}$. PAHs with two rings, accounting for $2.71 \%$ of the all PAHs, are Nap, Ace, Acy and Flo. Ace and Flo have low average concentrations of $34.0 \mathrm{ng} / \mathrm{g}$ and $12.4 \mathrm{ng} / \mathrm{g}$, taking percentages of $0.57 \%$ and $0.21 \%$, less than $1 \%$. What' more,

Table 1. Distribution characteristics of PAHs in topsoils of Xiaodian sewage irrigation area.

\begin{tabular}{|c|c|c|c|c|c|}
\hline & MAX & MIN & AVERAGE & \multirow{2}{*}{$\begin{array}{c}\text { Standard } \\
\text { Deviation } \\
(\mathrm{n}=31)\end{array}$} & \multirow{2}{*}{$\begin{array}{l}\text { Coefficient } \\
\text { of Variance }\end{array}$} \\
\hline & (ng/g) & (ng/g) & (ng/g) & & \\
\hline Nap & 394.57 & 4.07 & 83.93 & 102.57 & 1.22 \\
\hline Acy & 377.65 & 0.46 & 34 & 80.62 & 2.37 \\
\hline Ace & 57.78 & ND & 12.4 & 17.9 & 1.44 \\
\hline Flo & 199.88 & 0.76 & 31.28 & 49.81 & 1.59 \\
\hline Phe & 1940.88 & 7.19 & 247.63 & 405.85 & 1.64 \\
\hline Ant & 410.09 & 7.32 & 67.55 & 82.07 & 1.21 \\
\hline Fla & 3776.75 & 1.93 & 396.01 & 808.26 & 2.04 \\
\hline Pyr & 2870.02 & 1.11 & 303.83 & 633.17 & 2.08 \\
\hline $\mathrm{BaA}$ & 2301.95 & 1.67 & 200.96 & 480.37 & 2.39 \\
\hline Chry & 5776.52 & 10.27 & 998.91 & 1579.81 & 1.58 \\
\hline $\mathrm{BbF}$ & 4770.84 & 3.21 & 707.06 & 1224.03 & 1.73 \\
\hline $\mathrm{BkF}$ & 8280.27 & 5.72 & 587.3 & 1525.72 & 2.6 \\
\hline $\mathrm{BaP}$ & 7444.09 & 4.22 & 868.07 & 1718.06 & 1.98 \\
\hline InP & 5371.45 & ND & 604.13 & 1129.16 & 1.87 \\
\hline DiA & 1050.63 & ND & 141.55 & 233.34 & 1.65 \\
\hline BghiP & 6918.69 & ND & 733.32 & 1491.51 & 2.03 \\
\hline$\Sigma$ PAHs & 46432.85 & 47.94 & 5969.81 & 10785.67 & 1.81 \\
\hline
\end{tabular}

"ND" stands for this matter was not been found. 


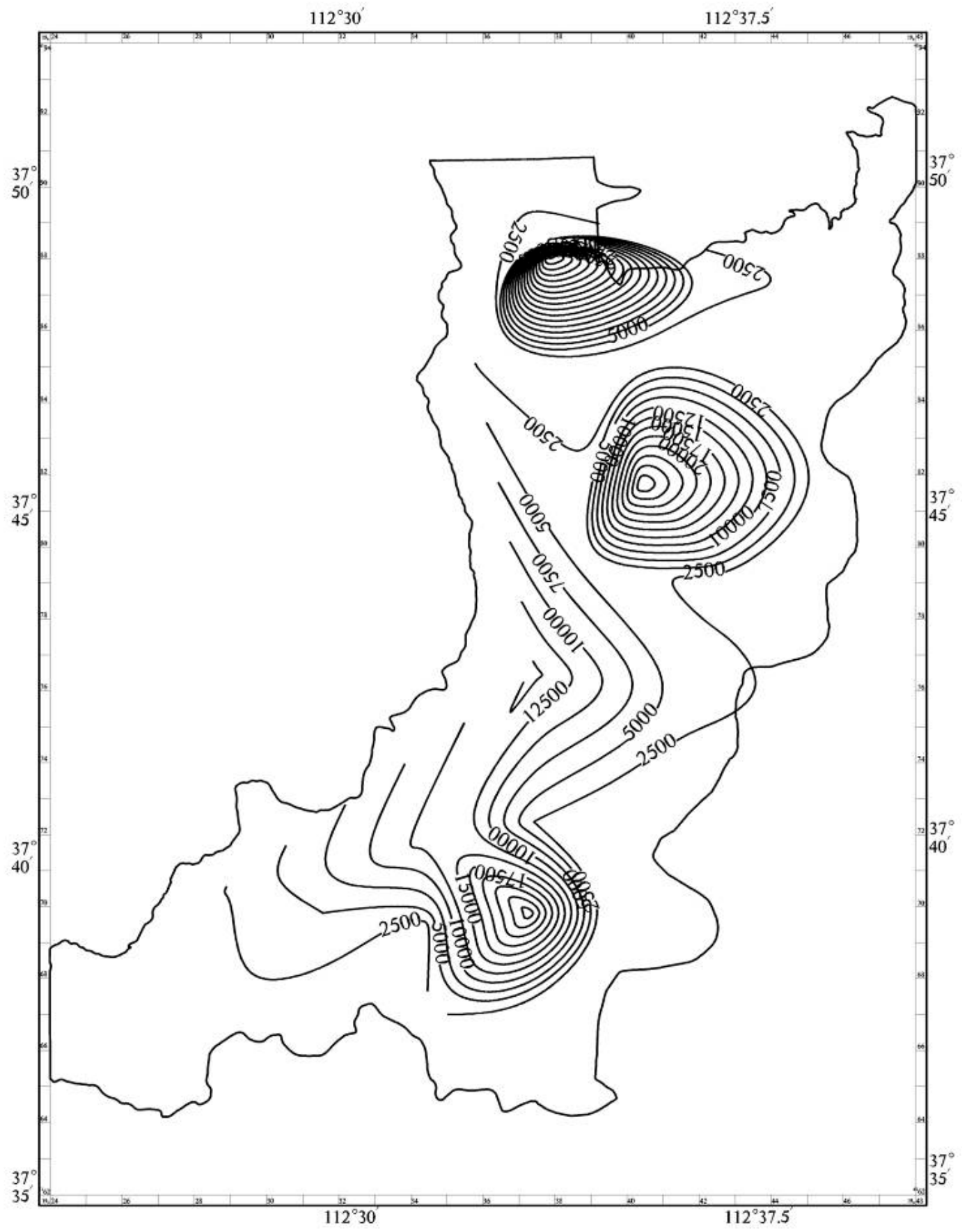

Figure 2. Concentration isoline map of $\Sigma$ PAHs in topsoils of Xiaodian sewage irrigation area (unit: ng/g).

Ace is a detected object with a lowest concentration. PAHs with 3 rings are Phe, Ant and Fla, whose percentages are $4.1 \%, 1.13 \%$ and $6.63 \%$. They account for $11.91 \%$ of the total PAHs. PAHs with for rings and more than 4 rings are the main and important pollutants in topsoils of Xiaodian District. Those with 4 rings take the largest percentage $46.87 \%$. Chry and BbF are more than $11 \%$ of $\Sigma$ PAHs separately. Chry, accounting for $16.73 \%$ of $\Sigma$ PAHs in topsoils, is the most important pollutant with a concentration of $998.91 \mathrm{ng} / \mathrm{g}$, higher than any other kind of PAHs. The total percentage of PAHs with more than 5 rings is $38.51 \%$. Except DiA with a little lower concentration, InP and $\mathrm{BaP}$ both have higher concentrations and have the percentages of more than $10 \%$ separately. BghiP, a kind of PAHs with 6 rings, accounts for $12.28 \%$ of all PAHs. The results showed that the main input of PAHs is combustion source, and the main pollution source in this area is fired coal. 
The area where the concentration of $\Sigma$ PAHs in topsoils of Xiaodian District is higher than other areas is located around Xiaodian Street Office. This is closely related with that area which is the economic and administrative center of Xiaodian District, a dense population, a developed industry and a frequent coal-fired use. In addition, this area has a relatively flat terrain and the surrounded places are open, easily to accept PAHs pollution carried by the atmosphere from northwest. Furthermore, the relationship between the concentration of $\Sigma$ PAHs and TOC in topsoils showed a positive correlation.

The concentrations of $\Sigma$ PAHs range from 47.94 to $46432.85 \mathrm{ng} / \mathrm{g}$. Except that the sample SS-10 has the highest concentrations of Ace, InP and DiA and the sample SS-30 has that of Chry, all other highest concentrations of PAHs happened in the sample SS-1, as well the highest concentration of $\Sigma$ PAHs. The samples in which the concentration of $\Sigma$ PAHs are larger than 10,000 ng/g are SS-1, SS-10, SS-15, SS-21 and SS-30. The results showed above and the fact that all the 5 samples are located nearby the waste canal, reasonably explain the distribution of PAHs is closely related with sewage channel. The sample SS-1, located in the canal dam of Qinxian village, next to the sewage channel, is surrounded by residential buildings where there are some streets and dump pits. The lithologic-character of this topsoil sample is wet black dauk with many types of gravel. The topsoils in this place have been carried here to fill in the canal for over 10 years from an external place. The concentration of TOC in this sample reaches up to $7.87 \%$, which is the highest in all the samples. Meanwhile, $\Sigma$ PAHs here have a concentration of $46432.85 \mathrm{ng} / \mathrm{g}$ higher than any other samples.

SS-18, located in Xigia village, has the minimum concentration of $\mathrm{PPAHs}$ and that of all single components. The area within a hundred miles around the sample SS-18 is overgrown with weeds. A large number of silt sediments and saline-alkali soil can be seen there. It is estimated that the soil here was originally a field of swamp, rarely affected by human activity, fired-coal and factories. It is worth noting that this sample is located outside the irrigation area. The sample SS-11, located in the clean irrigation area, has a $\Sigma$ PAHs concentration of $1743.71 \mathrm{ng} / \mathrm{g}$, not very low, quite possibly affected by the nearby Wusu airport. Estimated to be impacted by atmospheric dry and wet deposition, the sample SS-3 located in Dong Mountain has a $\mathrm{SPAHs}$ concentration of $903.76 \mathrm{ng} / \mathrm{g}$.

The PAHs produced by natural causes and plants' synthetic generally has a concentration between 1 - 10 ng/g. As a result, the topsoils in Xiaodian District are polluted by human activity in varying degrees.

Figure 3 shows the average percentage content of PAHs in topsoils of the research area. The abscissa on

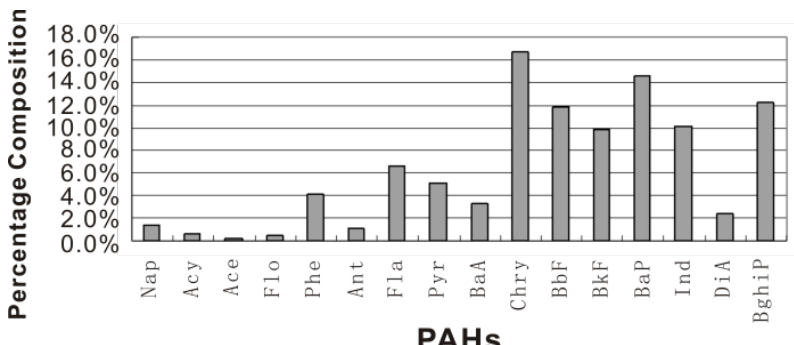

Figure 3. The average percentage composition of PAHs.

behalf of different kinds of PAHs, they are listed in order from left to right: Nap, Acy, Ace, Flo, Phe, Ant, Fla, Pyr, $\mathrm{BaA}$, Chry, BbF, BkF, BaP, InP, DiA and BghiP. According to Figure 3, Chry, with an average concentration of $998.91 \mathrm{ng} / \mathrm{g}$, higher than any other kind in the all 16 PAHs, accounting for $16.73 \%$ of all the PAHs pollutants, is the major pollutant in the study area. Other PAHs with more than 4 rings have a relatively higher concentration as well. This indicates that the main source of PAHs in the study area comes from the combustion.

Maliszewska Kordybach proposed that according to the concentration of $\Sigma$ PAHs in soil, soil can be graded into 4 levels: when the concentration is less than 200 $\mathrm{ng} / \mathrm{g}$, the soil is considered to be clean, when it is between 200 - $600 \mathrm{ng} / \mathrm{g}$, the soil is slightly polluted, when it ranges from 600 to $1000 \mathrm{ng} / \mathrm{g}$, soil is polluted moderately, when it is larger than $1000 \mathrm{ng} / \mathrm{g}$, the soil is heavily polluted. This standard is widely applied to distinguish whether soil is polluted in Europe [10]. Based on this standard, sample SS-18 is a clean soil, sample SS-31 is polluted slightly, and samples SS-4, SS-17, SS-19, SS-22, SS-24, SS-26 are polluted moderately, and the rest samples are all polluted heavily. 23 of all 31 topsoil samples have been heavily polluted, especially those located nearby developed industrial townships and irrigation channels. Consequently, the topsoils in Xiaodian District were polluted heavily and obviously effected by industrial townships and sewage irrigation. It is worth paying more attention to.

The concentrations of $\Sigma$ PAHs in topsoils of the target area are higher than that in the industrial area of Linz, a industrial city in Australia (the average is $1450 \mathrm{ng} / \mathrm{g}$ ) [11], even higher than that in the port city of Tallinn in Estonia (35.5 - 26,300 ng/g) [10] and in Dalian (6510 5730 ng/g) [12]. This result illustrates that the topsoils are strongly influenced by coal burning.

\section{Acknowledgements}

This research was funded by National Natural Science Foundation of China (No. 40830748 and No.40972156). The authors would like to thank Zhao Xu, Xiang Qingqing, Li Feng, Liu Yuan, Liu Lian, Tao Zhihao for their help in sampling and sample treatment. 


\section{REFERENCES}

[1] X. J. Wang, Y. Zheng, R. M. Liu, B. G. Li, J. Cao and S. Tao, "Medium Scale Spatial Structures of Polycyclic Aromatic Hydrocarbons in the Topsoil of Tianjin Area," Part B Journal of Environment Science and Health, Vol. 38, No. 3, 2003, pp.327-335. http://dx.doi.org/10.1081/PFC-120019899

[2] S. Tao, Y. H. Cui, F. L. Xu, B. G. Li, J. Cao, W. X. Liu, G. Schmitt, X. Wang, W. Shen, B. P. Qing and R. Sun, "Polycyclic Aromatic Hydrocarbons (PAHs) in Agricultural Soil and Vegetables from Tianjin," Science of the Total Environment, Vol. 320, No. 1, 2004, pp. 11-24. http://dx.doi.org/10.1016/S0048-9697(03)00453-4

[3] M. B. Yunker, R. W. Acdonald and R. Vingarzan, "PAHs in the Fraser River Basin: A Critical Appraisal of PAH Ratios as Indicators of PAH Source and Composition," Organic Geochemistry, Vol. 33, No. 4, 2002, pp.489-515. http://dx.doi.org/10.1016/S0146-6380(02)00002-5

[4] D. Broman, C. Naf, C. Roiff and Y. Zebuhr, "Occurrence and Dynamics of Polychlorinated Dibenzo-p-Dioxins and Dibenzofurans and Polycyclic Aromatic Hydrocarbons in the Mixed Surface Layer of Remote Coastal and Offshore Waters of the Baltic,” Environmental Science and Technology, Vol. 25, No. 11, 1991, pp. 1850-1864. http://dx.doi.org/10.1021/es00023a002

[5] P. Patnaik, In: P. Patnaik, Ed., Handbook of Environmental Analysis, CRC Press, Boca Raton, 1997, p. 165. http://dx.doi.org/10.1201/9781420050608

[6] P. T. Williams, "Sampling and Analysis of Polycyclic Aromatic Compounds from Combustion Systems-A Re- view," Journal of the Energy Institute, Vol. 63, 1990, pp. 22-30.

[7] USDHHS, “Toxicological Profile for Polycyclic Aromatic Hydrocarbons," US Department of Health and Human Services, 1995, p. 482.

[8] Boonyatumanond, Ruchaya, Wattayakom. "Distribution and Origins of Polycyclic Aromatic Hydrocarbons (PAHs) in Riverine, Estuarine, and Marine Sediments in Thailand," Manne Pollution Bulletin, Vol. 52, No. 8, 2006, pp. 942956. http://dx.doi.org/10.1016/j.marpolbul.2005.12.015

[9] K. C. Jones, J. A. Straford and K. S. Waterhouse, “Organiccontaminants in Welsh Soils: Polycyclic Aromatic Hydrocarbons," Environmental Science \& Technology, Vol. 23, No. 5, 1989, pp. 540-550. http://dx.doi.org/10.1021/es00063a005

[10] M. Trapido, "Polycyclic Aromatic Hydrocarbons in Estonian Soil: Contamination and Profiles,” Environmental Pollution, Vol. 105, No. 1, 1990, pp. 67-74. http://dx.doi.org/10.1016/S0269-7491(98)00207-3

[11] P. Weiss, A. Riss and E. Gschmeidler, "Investigation of Heavy Metal, PAH, PCB Patterns and PCDD/F Profiles of Soil Samples from an Industrialized Urban area (Linz, Upper Austria) with Multivariate Statistical Methods,” Chemosphere, Vol. 29, No. 9-11, 1994, pp. 2223-2236. http://dx.doi.org/10.1016/0045-6535(94)90390-5

[12] Z. Wang, J. W. Chen and X. L. Qiao, "Distribution and Sources of Polycyclic Aromatic Hydrocarbons from Urban to Rural Soils: A Case Study in Dalian, China," Chemosphere, Vol. 68, No. 5, 2007, pp. 965-971. http://dx.doi.org/10.1016/j.chemosphere.2007.01.017 